\title{
Henoch-Schönlein Purpura as a Presentation of Chronic Hepatitis B Infection
}

\author{
MAHMUDA BEGUM, ${ }^{1}$ MD. MANJURUL HAQUE, ${ }^{2}$ HUMAYRA JESMINE TRISHA, ${ }^{3}$ \\ A.F. M. HAFIZUR RAHMAN, ${ }^{4}$ HAM NAZMUL AHASAN ${ }^{5}$
}

\begin{abstract}
:
Henoch-Schönlein Purpura (HSP) is characterized by presence of classical triad of palpable purpura, arthritis and abdominal pain '. HSP may be triggered by bacterial and viral infections, eg. Hepatitis B viral infection. Chronic hepatitis $B$ infection may present with extra hepatic menifestations, vasculitis is an important one and poly arteritis nodosa is more commonly seen. A 30 years old lady presented with abdominal pain, palpable rashes over trunk, lower limb, which were consistent with HSP along with joint pain more on knees and ankles. She was diagnosed as a case of chronic hepatitis. HSP is not very uncommon among patients attending hospitals of Bangladesh, but its relation with Hepatitis $B$ virus $(H B V)$ or any other infective agent is not always searched. In our case HSP presented as an extra hepatic manifestation of chronic hepatitis $B$ infection. The extra hepatic manifestations of chronic hepatitis $B$ are associated with deposition of circulating HBV Ag-Ab immune complexes.
\end{abstract}

Keywords: Henoch-Schönlein Purpura, Chronic Hepatitis B infection.

\section{Introduction:}

Henoch-Schönlein Purpura also referred as "Anaphylactoid Purpura" is a small vessel vasculitis, characterized by palpable purpura, most commonly distributed over the lower limbs and buttocks, arthralgias, gastrointestinal signs and symptoms and glomerulonephritis ${ }^{2}$. HSP can develop after infections with streptococcus( beta hemolytic Lancefield classification A), adenovirus, herpes simplex, hepatitis B, coxsackie virus, parvo B19, helicobacter pylori, ${ }^{3}$ measles, mumps, rubella, mycoplasma and numerous others ${ }^{4}$. Drugs can cause HSP as idiosyncratic reaction, drugs like vancomycin, cefuroxime, ACE inhibitors eg. enalapril, captopril, anti inflammatory drugs eg. Diclofen. $35 \%$ of cases there may not be any of these causes. ${ }^{4}$

\section{Case report:}

A 30 years old married muslim lady, mother of 2 sons, was admitted in medicine unit of Dhaka Medical College Hospital in December, 2012, with the complains of abdominal pain for 1 month and rashes over her trunk and lower limbs for 25 days. Her abdominal pain was located in epigastric region, colicky in nature and had no radiation; initially pain aggravated with taking meals and relieved with taking antiulcerants. There was no history of nausea/vomiting. 5 days

1. Registrar, Department of Respiratory Medicine, DMCH.

2. Assistant Registrar, Department of Medicine, DMCH.

3. Indoor Medical Officer, Department of Medicine, DMCH.

4. Honorary Medical Officer, Department of Medicine, DMCH

5. Professor \& Head, Department of Medicine, DMCH

Correspondence: Dr Mahmuda Begum, Registrar, Respiratory Medicine, DMCH. email: mahmuda_dmc_k57@yahoo.com. cell: $+88-01553595989$ later she noticed reddish itchy painful rashes over her lower limbs. Rashes spread to buttocks and later to upper limbs. 56 days after eruption, rashes resolved with blackish hue and left no ulceration or scarring. During her course of illness rashes appeared in crops for 3-4 episodes. She was suffering from joint pain for last 4 months. Pain was more on both ankles and knees, more in the morning and gradually decreased with activities. There was no eye complain, her bowel and bladder habits were normal, no history of hematuria/ bleeding per rectum. Her past medical history revealed that she had suffered from recurrent episodes of jaundice for 4 years each time cured with conservative management. One year back she was diagnosed as a case of chronic hepatitis B. There was no history of features of decompensation like ascites or encephalopathy. She gave

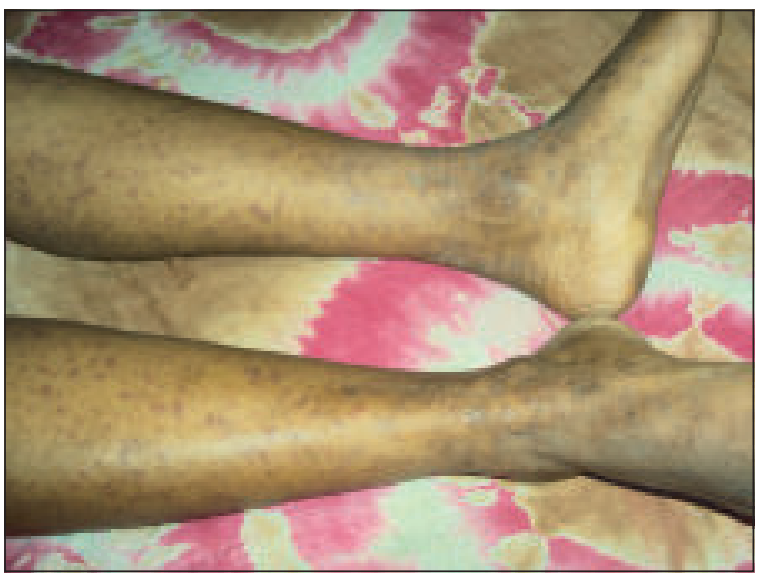

Fig.-1: Characteristic rashes of Henoch Schonlein Purpura involving both lower limbs of the patient. 


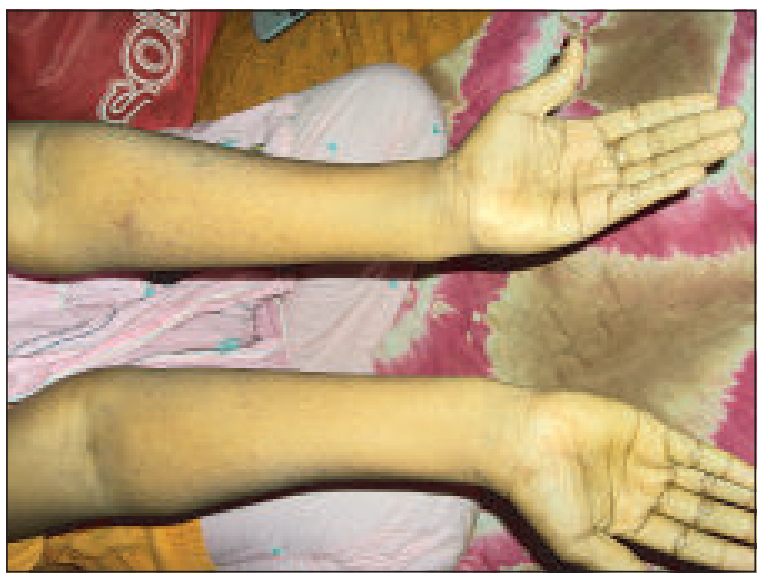

Fig.-2: Rashes involving the upper limbs of the patient.

no history of oral ulcer/ photosensitivity/ rashes over face/ fetal loss; her menstrual cycle is regular. She is normotensive and nondiabetic. On examination, all vital parameters of the patient were within normal limit. She was not anemic or icteric. There were numerous purpuric palpable rashes over extensor surface of lower limbs, flexor surface of upper limbs and over buttocks. Rashes were mostly reddish in colour, did not blanch on pressure. Other systemic examinations were normal.

Her investigations revealed total WBC count- 13,500/cumm, neutrophil $70 \%$, lymphocyte $25 \%$, monocyte $0.5 \%$, eosinophil $2.8 \% \mathrm{Hb} \% 13.5 \mathrm{gm} / \mathrm{dl}$, TPC normal, ESR was $80 \mathrm{~mm}$ in $1^{\text {st }}$ hour, CRP not raised, urine R/M/ E was not significant. Prothrombin time $13 \mathrm{sec}$, SGPT 51u/ml, S. bilirubin $0.74 \mathrm{mg} /$ dl, S. creatinine $1.1 \mathrm{mg} / \mathrm{dl}$. S. electrolyte, CXR (P/A), ECG,Xray of whole abdomen with both dome diaphragm(a/p), USG of whole abdomen revealed no abnormality. Endoscopy of upper GIT was normal . Serology: HBsAg positive, Anti HBc IgM negative, Anti $\mathrm{HBc}$ total positive, $\mathrm{HBe} \mathrm{Ag}$ negative. HBV DNA 5.2x 10² IU/ml, $2.56 \times 10^{3}$ copies $/ \mathrm{ml}$. ANA was negative. RA factor negative, c-ANCA, p-ANCA negative. Liver biopsy report showed section of liver reveal moderate piecemeal necrosis and mild lobular necrosis. The portal area showed moderate infiltrate of chronic inflammatory cells and periportal fibrosis; mild chronic hepatitis, $\mathrm{HAI}=7$, Knodell score $=8$. Skin biopsy was consistent with HSP.

\section{Discussion:}

The clinical features of chronic hepatitis B infection ranges from asymptomatic infection to debilitating or end stage liver failure. Chronic hepatitis B may present with some extra hepatic features that depends on deposition of HBV Ag- Ab immune complexes in various organs, features like; arthritis and arthralgia is more common, generalized vasculitis (PAN), small vessel vasculitis, immune complex mediated glomerulonephritis are less common ${ }^{2}$.
The characteristics and distribution of rashes in our patient are clinically suggestive of HSP, although our patient had severe abdominal pain, unlike most cases of HSP, renal involvement and GI bleeding is not evident in her ${ }^{5}$. Palpable purpura is seen in virtually all patients; most patients develop polyarthralgias, more in ankle and knees, in the absence of frank arthritis. Gastrointestinal involvement, which is seen in almost $70 \%$ of pediatric patients, is characterized by colicky abdominal pain usually associated with nausea, vomiting, diarrhea, or constipation and is frequently accompanied by the passage of blood and mucus per rectum; bowel intussusception may occur. Renal involvement occurs in $10-50 \%$ of patients and is usually characterized by mild glomerulonephritis leading to proteinuria and microscopic hematuria, with red blood cell casts in the majority of patients ; it usually resolves spontaneously without therapy. Rarely, a progressive glomerulonephritis will develop. In adults, presenting symptoms are most frequently related to the skin and joints, while initial complaints related to the gut are less common. Although certain studies have found that renal disease is more frequent and more severe in adults, this has not been a consistent finding. However, the course of renal disease in adults may be more insidious and thus requires close follow-up. Myocardial involvement can occur in adults but is rare in children.

Recurrent vasculitis and palpable purpura can occur in HBsAg-positive chronic hepatitis with circulating immune complexes which contained HBsAg, immunoglobulin $\mathrm{M}$ and $\mathrm{G}$ as well as complement (C) with no evidence for HBV replication. HBsAg, IgM and $\mathrm{C} 3$ were demonstrable in the arteriolar walls of the skin. The results support the concept that complement activating immunecomplexes containing HBsAg and IgM anti HBs play a role in the pathogenesis of vasculitis as described here ${ }^{6,7}$. Like chronic persistent hepatitis B, acute viral hepatitis B may also be complicated with $\mathrm{HSP}^{8,9}$.

The ultimate outcome of chronic HBV infection appears to depend on the duration and severity of liver injury during the immune clearance phase. About $2.1 \%$ of patients with chronic type B hepatitis develop cirrhosis each year. Patients who have a severe acute exacerbation complicated by subacute hepatic failure or who have recurrent episodes of acute exacerbations with bridging hepatic necrosis are more likely to develop cirrhosis ${ }^{13}$.

Henoch- Schonlein Purpura with chronic hepatitis B has been a subject of challenge for management. Treatment of HSP requires high dose prednisolone. There are few evidence that of increase of patient's viral load thus flare 
of the disease with immunosuppressive drugs, eg. Lamivudine,zidovudine and interferon alpha, and with recurrent episodes of HSP after treatment have also been reported $^{10,11}$. A drug reaction, autoimmune diseases, tumours and HIV infection need to be excluded here.How ever there is no alternative to treating chronic hepatitis B with current drugs.

\section{Conclusion:}

Each year a lot of patient come to tertiary level hospitals of Bangladesh and clinically diagnosed as HSP, most of them are labeled as due to idiopathic causes. This might be the first case report on Henoch Schonlein Purpura caused by Hepatitis B in Bangladesh. Although rare but we should keep in mind about this co-existence.

\section{Conflict of Interest : None}

\section{References:}

1. Kraft DM, Mckee D, Scott (1998), Henoch-Schonlein purpura: a review. American Family Physician 58(2): 405-8, 411.

2. Carol A. Longford, Anthony S. Fauci, The Vasculitis Syndromes, Longo, Fauci, Kasper, Hauser, Jameson, Loscolzo eds, Harrison's Principles of Internal Medicine, $18^{\text {th }}$, The McGraw-Hill Companies, Inc. 326: 2797-98.

3. Saulbury FT, Henoch-Schonlein purpura, Current opinion in Rheumatology. 2001; 13(1): 35-40.
4. Rai A, Nast C, Adler S, Henoch-Schonlein purpura nephritis. Journal of American Society of Nephrology. 1999; 10(12): 2634-44.

5. Diehl MP et al. Elderly onset Henoch-Schonlein purpura: a case series and review of literature. J Am Geriatr Soc. 2008; 56(11): 2157-9.

6. Gower RG, Sausker WF, Kohler PF, Thorne GE, McIntosh RM. Small vessel vasculitis caused by hepatitis B virus immune complexes. Small vessel vasculitis and HBsAg. J Allergy Clin Immunol. 1978; 62(4): 222-8.

7. Stemerowicz R, Moller B, Lobeck H, Oertel J, Hopf U. Schoennlein-Henoch purpura in chronic HbsAg- positive hepatitis. Immun Infekt. 1988; 16(1): 12-5.

8. Maggiore G, Martini A, Grifeo S, De Giacomo C, Scotta MS. Hepatitis B virus infection and Schonlein-Henoch prpura. Am J Dis Child. 1984; 138(7): 681-2.

9. Tareeva IE, Filimonova RG, Nikololaev Alu, Androsova SO, Mikhailov MI, Miroshnichenko NG. Hemorrhagic vasculitis and the hepatitis B virus. Ter Arkh. 1993; 65(6): 17-9.

10. Chu CM. Natural history of chronic hepatitis B virus infection in adults with emphasis on the occurrence of cirrhosis and hepatocellular. J Gastroenterol Hepatol. 2000; 15: 25-30.

11. Braun S, Ramaker J, Dippel E, Zouboulis CC, SchonleinHenoch purpura associated with hepatitis B in a patient with HIV infection. Dtsch Med Wochenschr. 2001; 126(5): $103-7$. 